\title{
Addressing food poverty in systems: governance of food assistance in three European countries
}

Francesca Galli, $1 \bowtie$

Phone 00390502218975

Email francesca.galli@unipi.it

Francesca Galli is currently a researcher at the Department of Agriculture, Food and Environment, University of Pisa (Italy), where she teaches a masters' course on policies for the food system policies. She completed a Ph.D. in 'Economics and Territory', University of Tuscia (Viterbo, Italy) with a thesis on multi-criteria assessment of impacts on the EU food quality polity and Geographical Indications. She eentinued to worked for six years as a postdoctoral researcher (University of Pisa, Italy) on European FP7 and H2020 multiactor research projects (FOODLINKS; GLAMUR; TRANSMANGO, SALSA, ROBUST). Her research interests focuses on food systems and food and nutrition security, socio-economic and environmental impacts of sustainable agriculture and food, suppert policies for-smallholder farming and rural development policies at local and regional levels, public food procurement, food supply chain economics and agri-food standards.

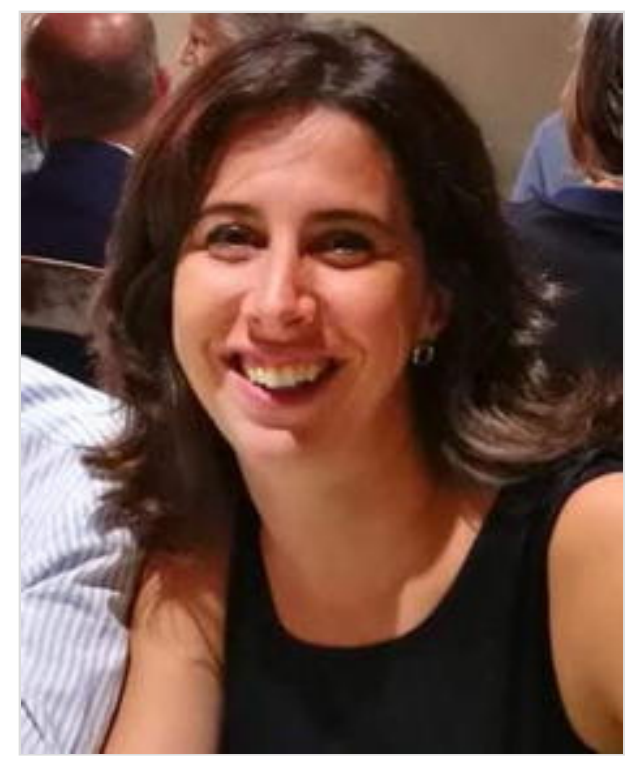


Aniek Hebinck, 2,3,4

Email aniek.hebinck@su.se

Email aniek.hebinck@ouce.ox.ac.uk

Aniek Hebinck is a doctoral candidate at the Stockholm Resilience Centre of Stockholm University in Sweden. Her PhD focuses the role of urban food initiatives in shaping sustainable food systems and addressing food system failings, such as food poverty and ecological degradation. This is based on work done in several food systems change projects. Firstly, she has been exploring cases of food assistance and urban food strategy development while working at Wageningen University for the project TRANSMANGO (transmango.eu, FP7). Secondly, she currently works as a researcher at the food systems group of the Environmental Change Institute of the University of Oxford on the projects SUSFANS ( susfans.net, H2020) and SENTINEL (UK GCRF project).

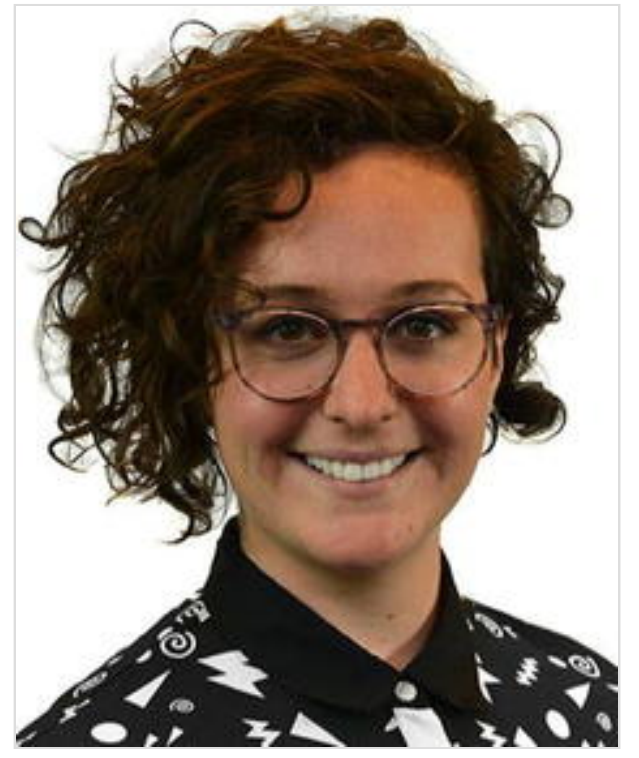

Bridir AQ1 Carroll, 5

Email Bridin_Carroll@health.gov.ie

Bridin Carroll completed her PhD on local and sustainable food at NUI Galway in 2013. She maintained her interest in this research topic by completing a short study on halal food while working as a teaching associate in the geography department of the University of Birmingham (2013-2014). Brídín then carried out a short project for the National Economic and Social Council (Ireland, 2014), examining green procurement and sustainable food and drink assurance schemes. From 2014 to 2018, she was a post-doctoral researcher at University College Dublin, working on TRANSMANGO, a study of the 
vulnerabilities and resilience of the European food system. With the end of this project, Brídín's research interests have moved to the topic of healthy ageing; since February 2018 she has been working as a post-doctoral researcher on the Healthy and Positive Ageing Initiative (Department of Health, Government of Ireland).

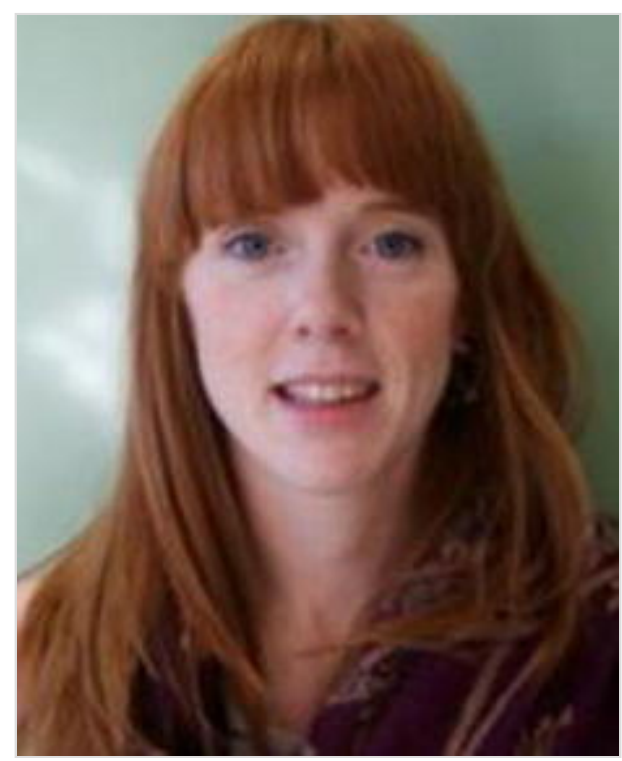

1 Department of Agriculture Food and Environmen AQ2 , University of Pisa, via del Borghetto 80, 56124 Pisa, Italy

2 Stockholm Resilience Centre, Stockholm University, Stockholm, Sweden

3 Food Systems Group, Environmental Change Institute, University of Oxford, Oxford, UK

4 Rural Sociology Group, Wageningen University, Wageningen, The Netherlands

5 Healthy and Positive Ageing Initiative, Department of Health, Government of Ireland, Dublin, Ireland

Received: 19 April 2018 / Accepted: 17 October 2018

\section{Abstract}

Emergency food poverty relief is one of the possible entry points to understanding food poverty in affluent societies, whereas the visibility of food poverty relief initiatives has evolved, together with large-scale food recovery 
organizations and networks aiming at reducing and valorising food systems' surplus. There is a substantial diversity of actors and resources involved, resulting in differently shaped initiatives and programs. It can be described as a continuum encompassing third sector initiatives, large and small businesses, and institutional intervention programs: by bringing together institutions, companies, organisations and civil society, public-private food assistance addresses food poverty in a way that is not viable by any of these actors alone and by adopting context specific governance arrangements. This paper contributes to this debate with the analysis of governance relations in food assistance initiatives across different European countries (Italy, The Netherlands and Ireland). By approaching food assistance from a systems perspective, we further the understanding of these initiatives and their modes of governance. The case studies offer a mapping of food assistance by identifying functions and outcomes, actors and resources involved, and the links the initiatives have to those elements, thus highlighting where collaborative food poverty reduction takes place, that goes beyond traditional boundaries. Food assistance initiatives are a civil initiated response shaped by and complementing the social welfare and food systems in which they are embedded. The interpretation of food assistance functions leads to challenging the boundaries of food assistance and potentially triggering innovative approaches to improving food and nutrition security. Discussions show that while they have managed to find innovative and collaborative governance solutions to address the very immediate issues rather effectively, they do not negate the need for food system transformation to address the ultimate reasons for food poverty.

\section{Keywords}

Food poverty

Food assistance

Food systems

Governance arrangements

Francesca Galli and Aniek Hebinck contributed equally to this work.

\section{Introduction and aims}

\section{$\mathrm{AQ3}$}

Emergency food poverty relief, or food assistance, has been defined as the "provision of financial... [and material] assistance to those persons that find themselves in financial crisis" (ACOSS 2011). Its main objective is to respond to immediate and urgent needs through emergency food provisioning (Poppendieck 
1994), rather than addressing the root causes of those urgent needs. The importance of food assistance as one of the possible entry points to understanding food poverty in affluent societies is evidenced by the fact that since the years of economic crisis (2007-2008) the amount of academic literature on this topic has soared.

AQ4

Another important reason for the increased visibility of food poverty relief initiatives is that the scale and logistics of food assistance have changed in recent years. They have been evolving with the growth of large-scale food recovery organizations and networks aiming to reduce and valorise the food system's surplus (Hebinck et al. 2018; Arcuri et al. 2017; Caraher and Cavicchi 2014). Food assistance encompasses a broad range of actors and a mix of public-private resources including many different suppliers, food pantries, soup kitchens, social markets, shelters, school distribution programs, religious and non-religious organisations, and anti-hunger advocates and volunteers (Webb 2013). There is a substantial diversity of actors and resources involved, resulting in differently shaped initiatives and programs. It can be described as a continuum encompassing third sector initiatives, large and small businesses, and institutional intervention programs. By bringing together institutions, companies, organisations and civil society, public-private food assistance addresses food poverty in a way that is not viable by any of these actors alone (Rovati and Pesenti 2015).

Third sector actors who lead food assistance initatives do not claim to hold the answer to food poverty, aware of the limitations in their power to address the multidimensionality of ( food) poverty. Instead they emphasise the temporal imperative of their practices and they regard it as an extra tool for people to get back on their feet. Recent research shows that models of food charity have emerged rapidly (Hebinck et al. 2018; Elmes et al. 2016; Galli et al. 2016): food assistance organizations are beginning to diversify their work in ways that are socially innovative, reaching beyond more generic provisioning by food charity. This includes features of "community food security", for example workshops for nutritional cooking, employment and hospitality training programs, and community gardens (Vlaholias Vlaholias-West et al. 2018).

Food poverty alleviation is dependent on different factors within food assistance initiatives. These factors relate to their internal structures, such as delivery model, organisation and governance mode, and their ability to establish external connections. These are shaped by the specific cultural, economic, social and political vectors present in each food assistance initiative's context (Kim 2015). Diving deeper into the intent of a given organisation, quite often more personal 
factors emerge such as the intentions, backgrounds, and contextual operations of local food bank leaders and initiators (González-Torre and Coque 2016; Kim 2015).

Despite the growing interest in the topic, to date academic literature has given limited attention to the governance mechanisms of food assistance practices across high income countries, with few exceptions. ${ }^{2}$ Considering the role they have taken up, there is a need for structured insight in and comparison of food assistance experiences. This paper contributes to this debate with the analysis of governance relations in food assistance initiatives across different European countries, namely Italy, The Netherlands and Ireland. By approaching food assistance from a systems perspective (further explained in the Methods section), we further the understanding of these initiatives and their modes of governance. The case studies offer a mapping of food assistance by identifying functions and outcomes, actors and resources involved, and the links the initiatives have to those elements, thus highlighting where collaborative food poverty reduction takes place in the three case studies. This allows a deeper insight into the initiatives' relations on various levels - local, national, international - providing the basis for a greater understanding of food assistance governance.

The cases reflect both the commonalities and stark differences in process configurations, rules and technologies that can be found at territorial level (i.e. across and within countries). It is likely that variation could even be found between neighbouring countries and as such, the cases should not be considered representative of Northern or Southern European models of food assistance. In the discussion, we reflect on crosscutting aspects, specificities and limitations in the food assistance cases. We also reflect on the benefits of a systems perspective to food assistance and how it enables the identification of governance arrangements that go beyond traditional boundaries (Candel and Pereira 2017; van Meerkerk and Edelenbos 2017; Clark et al. 2016; Termeer and Bruinsma 2016; Lang and Ingram 2013). Importantly, the descriptions aim to show how the interpretation of food assistance functions leads to challenging the boundaries of food assistance, by adopting old practices or establishing of new ones, inclusion of new actors in the governance processes (from inside and outside of the food system, i.e. extended governance) and potentially triggering innovative approaches to improving food and nutrition security. Further, it exemplifies and emphasises the multifaceted nature of problems related to poverty (Rijke et al. 2012), requiring more collaborative and reflexive responses.

\section{Situating food poverty and food assistance}


During recent years of severe economic crisis, there has been renewed attention to food and nutrition security in relation to food systems' vulnerabilities (Rutten et al. 2018; Brunori et al. 2017; Gustafson et al. 2016; Cordell et al. 2009). Food security is a multidimensional phenomenon that is addressed at different scales and by multiple disciplines. It partly overlaps with food poverty and hunger, but it also touches on other dimensions (see Jones, et al. 2009 for a representation of different concepts relevant to food and nutrition insecurity). Household food insecurity has been effectively defined as "people's inability to acquire or consume an adequate or sufficient quantity of food in socially acceptable ways, or the uncertainty that one will be able to do so" (Fabian Commission 2015; Riches 2002; Radimer et al. 1992). In these terms, food poverty is conceptualised primarily as the lack of access to a safe and healthy diet, explained by inadequate income and poverty. It also relates to mental well-being, undermined by the sense of uncertainty and consequently fear, and the exclusion that occurs by not being able to partake of normal social activities (Riches and Silvasti 2014; Nikolic Nikolić et al., 2014; Dowler and O'connor 2012; Burns et al. 2010). AQ5

Situating and measuring food poverty within other and wider forms of poverty is not an easy task. Despite the increasing attempts to assess the phenomenon, the understanding of food poverty and how to address it remains limited. The reduction of people at risk of poverty and social exclusion is a part of Europe's key targets in its 2020 strategy. Its status is monitored via official statistics that consider three indicators (EU SILC data, 2016 2015): (1) the risk of poverty after social transfers (income poverty); (2) the share of households with very low work intensity; and (3) severe material deprivation. Captured under the third indicator is the "inability to afford a meal with meat, chicken, fish (or vegetarian equivalent) every second day". This currently stands as the only monitored element of food poverty in the EU. While there are stark differences across Europe, in 2015 the average portion of the EU28 population at risk of poverty is $21 \%$ (Fig. 1) and a little over $8 \%$ of the population is unable to afford a protein rich meal every second day (EU SILC data, 2016 2015). However, how these variables are monitored at country level and whether this captures the real extent of food poverty in Europe remains unclear.

\section{Fig. 1}

Percentage of people in EU28 countries at risk of poverty and social exclusion and the inability to afford a meal with meat, fish, chicken or a vegetarian equivalent every second day (EU SILC data, 2015). Paper casestudy countries highlighted. 
50

\section{5}

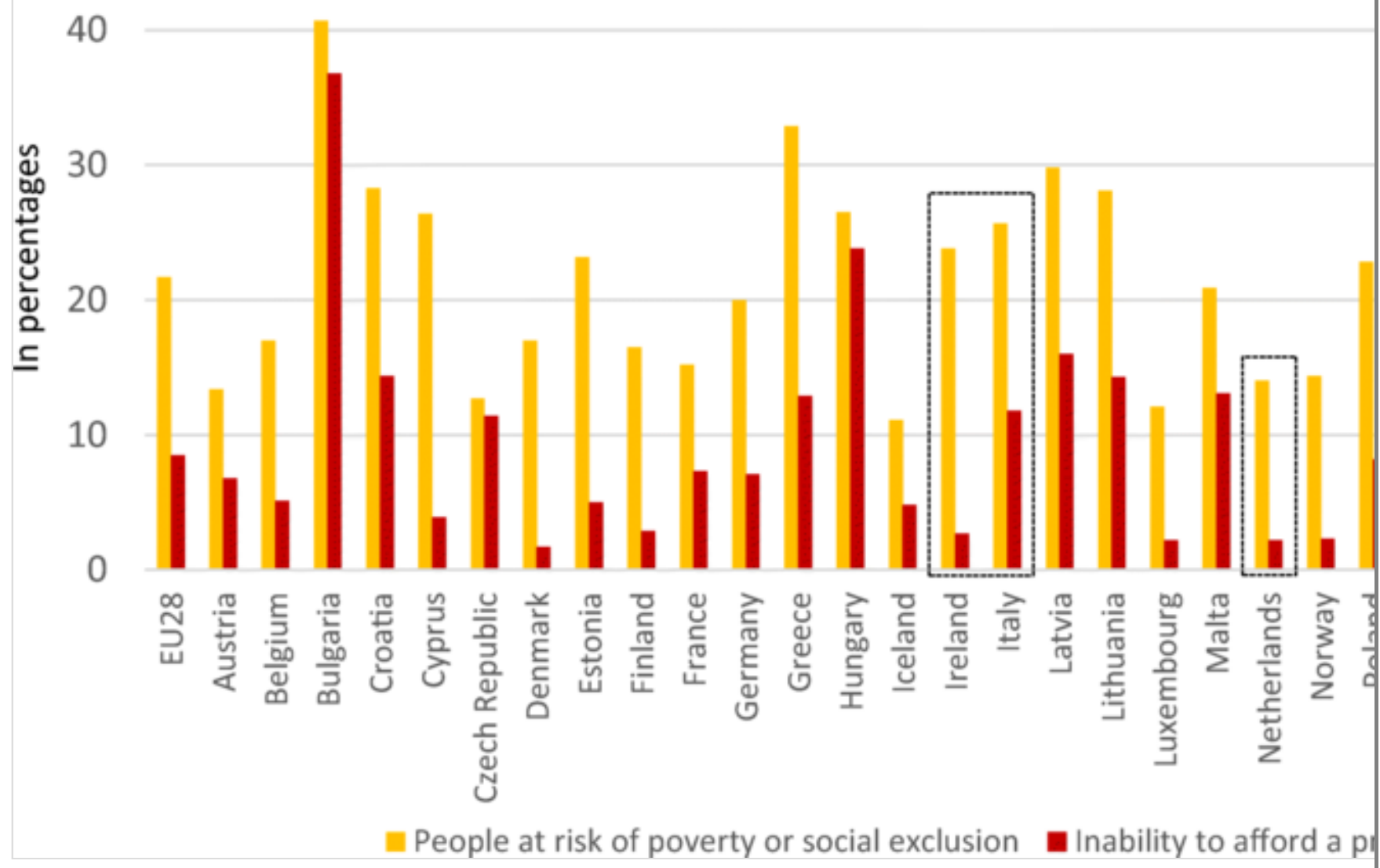

AQ6

Serving only the most vulnerable, the European Federation of Food Banks (FEBA) reports that in 2016 a total of 6.1 million people, spread over twentythree EU countries, ${ }^{3}$ have received meals through their member organisations. Several authors have raised concerns about the lack of systematic and official monitoring of food poverty and food assistance (Lambie-Mumford et al. 2014; Perez de ArminePérez de Armiño, 2014; Silvasti and Karjalainen 2014). Unofficial data collection by charitable organisations is likely to misrepresent reality, as it is aimed at keeping track of activities and performances and it is therefore by definition partial, incoherent and sometimes unreliable (Kneafsey et al. 2017). As such it is difficult to say what the actual status of food poverty and food assistance in Europe is. Despite monitoring limitations, what is visible is that food assistance initiatives have proliferated all over Europe and this can be considered a key signal of the urgent need for food poverty reduction (Hebinck et al. 2018; Fabian Commission 2015).

The fact that charitable food assistance initiatives represent the main response to food poverty in affluent societies is critically discussed by several authors. Some see this as a failure of welfare states in addressing the root causes of poverty, while others emphasize their complementarity to current welfare models (Riches 
2018; Arcuri et al. 2017; Lambie-Mumford 2017; Poppendieck 1998). Food assistance exemplifies a shift towards multi-sector collaborations - in the sense that they tend to include public, private and civil society institutions - generally encouraged by neo-liberal processes (Biebricher 2015) that have been shaping the global food economy. ${ }^{4}$ More and more, these initiatives take up vacant spaces within the welfare landscape, fulfilling functions which were previously assumed by state, while embedding of these food assistance initiatives into public poverty alleviation structures does not occur (Biebricher 2015). These developments are visible across developed countries globally, as shown by available literature on food assistance and public funding structures for food poverty alleviation (see Arcuri et al. 2017 for a review). For example, the Emergency Food Assistance Program (TEFAP) in the US institutionalised the private food distribution network by purchasing commodities for distribution through private charities. Here, the involvement of non-profit organisations is considered necessary to sustain federal outreach efforts (Fricke et al. 2015; Daponte and Bade 2000). Brazil has established a National Council for Food and Nutrition Security based on government, private sector and civil society efforts. This entails federal government initiatives, as well as local councils, taking responsibility for monitoring the use of resources and outcomes (Rocha 2009:61). Funding for Australian food assistance initiatives is highly variable and can differ between regions: while some receive funding from state departments and the Commonwealth, others regions rely almost primarily on agencies on the ground (Booth and Whelan 2014). For almost thirty years, the European Union had a program in place that rooted surplus food redistribution within the Common Agricultural Policy. Recently, this has been replaced by the Fund for the European Aid for the most Deprived (FEAD), which is part of EU social policy (Caraher 2015). In many cases, charitable organisations are the front-line distributors of FEAD resources, similar to the preceding policy. ${ }^{5}$ The program is made mandatory for all member states, but method of distribution is up to member states themselves. On the EU's part this reform indicates a renewed action on poverty, as it acknowledges its multi-dimensional character (FEAD, 2017; Regulation (EU) (2014)).

\section{Concepts and methodology}

The analysis builds upon systems thinking and previous research on collaborative forms of governance, as explored in the following sections. By using a systems perspective to review the governance modes in food assistance initiatives, we highlight the collaborative forms of governance they have established.

\subsection{A systems perspective to food assistance}


Systems thinking has become central to the study of food. A food systems approach frames the activities of food producers, processors, distributors, retailers and consumers as embedded in social, political, economic, historical and environmental contexts, and connects these activities to food security and socioenvironmental outcomes. The bio-geophysical, social, economic and political environments - described as drivers - influence how food system activities are performed; they impact on outcomes and in turn, generate feedbacks that alter the functioning of the system (HLPE 2017; Brunori et al., 2015; Ingram 2011; Ericksen 2008; FAO, 2008; Sundkvist et al. 2005).

AQ9

$\mathrm{AQ10}$

The use of a systems approach to understanding production, distribution and consumption dynamics in relation to food systems' outcomes helps to identify interactions, and provides a unifying framework to tackle complexity and change (Gustafson et al. 2016; Ingram 2011; Ericksen et al. 2010; Reynolds et al. 2007).

Important to systems thinking is the mapping of relationships and capturing of the dynamics within the system. For this we turn to Gharajedaghi (2011), who argues that understanding a problem in a holistic way requires "understanding structure, function, and process at the same time". Structure, functions and process represent three complementary aspects of a problem, situated within the wider context (i.e. the environment in which the system is placed): structures identify the components (assets, resources and actors) and the relational configurations among the components; functions define the outcomes or results produced by the interactions among the components; and processes indicate the series of activities and the knowledge needed to produce the outcome (Gharajedaghi 2011:90). Structure, functions, and processes, placed within the context, form an interdependent set of factors; "agency" implies the power to control or the ability to influence these factors, that characterise and impact more directly on the outcomes of the system. These factors can be internal (i.e., those directly controlled by actors and system activities) or external (i.e., those that cannot be controlled by actors and activities, but affect them to some extent) to the system's boundaries. In the case studies, we engage with food assistance system mapping to understand and make visible interactions, interconnections, the sequence and flow of activities, and the rules of the game that produce more or less desired functions.

Similar to the broader conceptualisation of food systems, food assistance entails numerous actors and resource streams that are interrelated into a system. Many food assistance actors collect and combine food donations with 'surplus' food food that, for many reasons, is not traded through regular market channels 
(Garrone et al. 2014a, b) - in direct and indirect contact with food system actors, including farmers, retailers, processors, and consumers. In addition, food assistance third sector actors often work in connection with public social services. For example, public social services re-direct a number of requests of help to third sector actors. As shown by the literature, a functional link has been established between welfare services and voluntary assistance, with varying degrees of intensity across different countries. Therefore, in reality, voluntary food assistance is a strategic component of the local welfare system responsible for combating poverty. Moreover, food assistance relies partly on public resources for food supply, as mentioned in relation to the European FEAD program. Hence, it can be stated that the specificity of food assistance systems lies in the interaction of actors, resources and processes belonging to different systems; it is where the food, welfare and third sector systems intersect.

\subsection{The role of governance}

A crucial element of food systems is governance, as it can greatly influence food and nutrition security outcomes (Moragues-Faus et al. 2017; Hospes and Brons 2016). Governance can broadly be described as "the interactions between public and/or private entities ultimately aiming at the realisation of collective goals" (Candel 2014, p.586; Termeer et al. 2015; McKeon 2014). While governance is traditionally associated with national governments, the responsibilities of states have changed over time by processes "associated with the dismantling of the welfare state" and has led to decentralisation of governance (Moragues-Faus and Marsden 2017, p. 275; Hebinck and Page 2017). Similarly, visible in food assistance is that these responsibilities are increasingly taken up via efforts from citizens, civil society organisations and local governments, who increasingly shape the governance of local food systems, which is key for addressing food poverty (Kim 2015).

Collaborative forms of governance are increasingly discussed in food systems as "processes and structures of public policy decision-making and management that engage people constructively across the boundaries of public agencies, levels of government, and/or the public, private and civic spheres in order to carry out a public purpose that could not otherwise be accomplished" (Moragues-Faus and Morgan 2015; Emerson et al. 2012, p2). One mode frequently mentioned is 'reflexive governance', which emphasises the necessity of continuous reviewing of the governance itself, with respect to the embedded frames, structure and patterns of action, as emphasised in food systems studies (see Duncan 2015a; Sonnino et al. 2014; Brunori et al. 2013; Marsden 2013; Hendriks and Grin 2007). The closely related 'adaptive governance' is more focused on addressing the uncertainties that are associated with complex systems and is often associated 
with governance of socio-ecological systems (see e.g. Rijke et al. 2012; Olsson et al. 2006; Folke et al. 2005). Embedded in the transition literature, is the notion of transition management (Wittmayer et al. 2015; Kemp et al. 2007), which particularly describes governance processes aimed towards a particular sustainability transition. Less frequently mentioned in the literature are concepts such as place-based governance, which describes governance directed at empowering of local communities (see George and Reed 2017) and private governance which is centred on private non-state actors (Fuchs et al. 2011; Pattberg 2006). Such collaborative and reflexive forms of governance attempt to address the key criticisms of dominant and more traditional governance structures (Stirling 2014; Marsden 2013; Voss and Bornemann, 2014Voß and Bornemann, 2011): firstly, what is seen as the inability of practitioners and policy-makers to sufficiently cope with complexity and uncertainties, often leading to the application of simplistic solutions to multifaceted problems (Rijke et al. 2012); secondly, collaborative governance can include a range of actors from different backgrounds that would otherwise not be included. As such they can theoretically give voice to marginalised groups and build upon a more diverse range of perspectives (Duncan 2015b; Scholte 2011); and thirdly, space for innovation can be created through the adoption of more collaborative frameworks that are more flexible compared to the traditional and rigid state bodies (Voss and Bornemann, 2014Voß and Bornemann, 2011).

\subsection{Materials and methods}

This research is qualitative in nature; a case study strategy was used for the exploration of food assistance and its systemic nature across three countries Italy, the Netherlands and Ireland. This research entails two levels of analysis: in-depth case studies in the three countries, and cross-case analysis. These three cases were selected as part of research carried out in the EU project

TRANSMANGO. Case studies were developed based on a methodology common to all national research teams of the project, including the three dealt with in this paper (Oostindie et al. 2016; Yin 2013). Each case study integrates desk research of available national academic and "grey" literature (policy documents, charities reports, secondary data, news articles) on the topic. Participant observation was used in all cases and included site-visits to the food assistance delivery points, food banks warehouses, direct participation in food collection (i.e. food drives), participation to local charities meetings, organisation of workshops, short conversations and informal interviews. These activities allowed researchers to 'place themselves within the research context' (Ponterotto 2006). Furthermore, in-depth and semi-structured interviews were used to address topics covering the food system, welfare and third sector actors (Arcuri et al. 2016; Carroll et al. 2016; Hebinck et al. 2015). These took place between September 2015 and June 
2016. The interviews were recorded, transcribed and coded. These codes related to the practices around food assistance delivery, sourcing of food and financial support, the internal organisation of the local level charities and secondary level food banks, the interactions with the institutional setting and new collaborations or arrangements. Analysis of food assistance systems entailed a comparative reading aimed at mapping actors internal and external to food assistance including public and private resource providers, the main relationships, and the outcomes in terms of percentage of food assistance recipients in relation to population at risk of food poverty.

\section{Results: The national case studies}

The case studies presented below provide an overview that cuts across food assistance system components - functions, structures and processes - as delineated at the beginning of the Concepts and methodology section. After a brief overview of the facts on how the food assistance initiatives came to be and their main features, an approximate indication of their outcomes is provided, by comparing the data on people at risk of poverty and social exclusion, material deprivation (related to food) with the number of food aid recipients. Then a description of the structure is developed and visualized in the figures (Figs. 2, 3 and 4). The figures identify the main actors - distinguished between internal and external to the food assistance systems - and map the interrelations (operational and institutional) by pointing to the main strengths and criticalities. The description of the cases is followed by the identification of cross-cutting emerging themes, which form the basis for critical reflection on governance in the food assistance initiatives at hand.

Fig. 2

Food assistance functions, actors, internal and external relations in Italy 


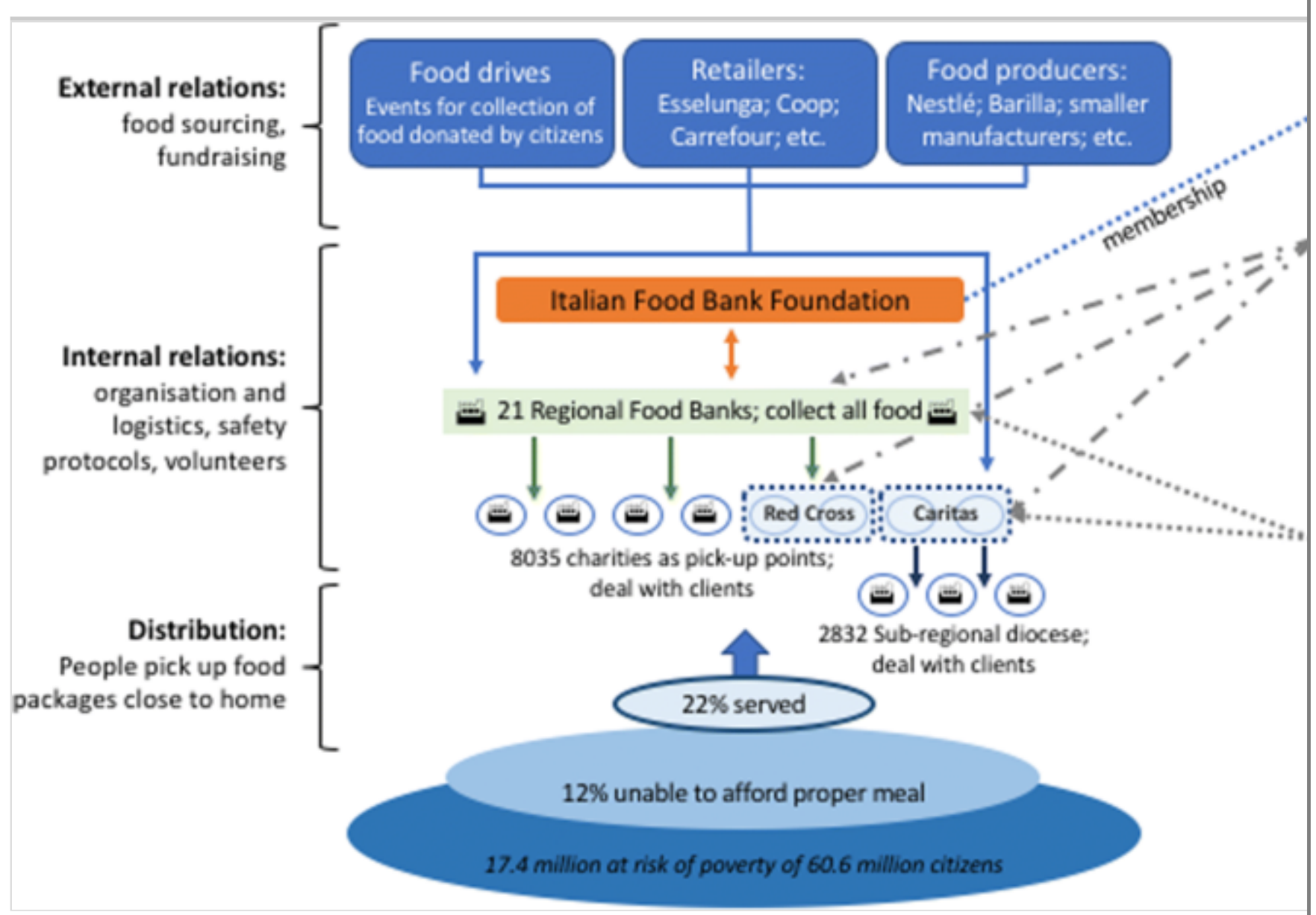

Fig. 3

Food assistance functions, actors, internal and external relations in the Netherlands 


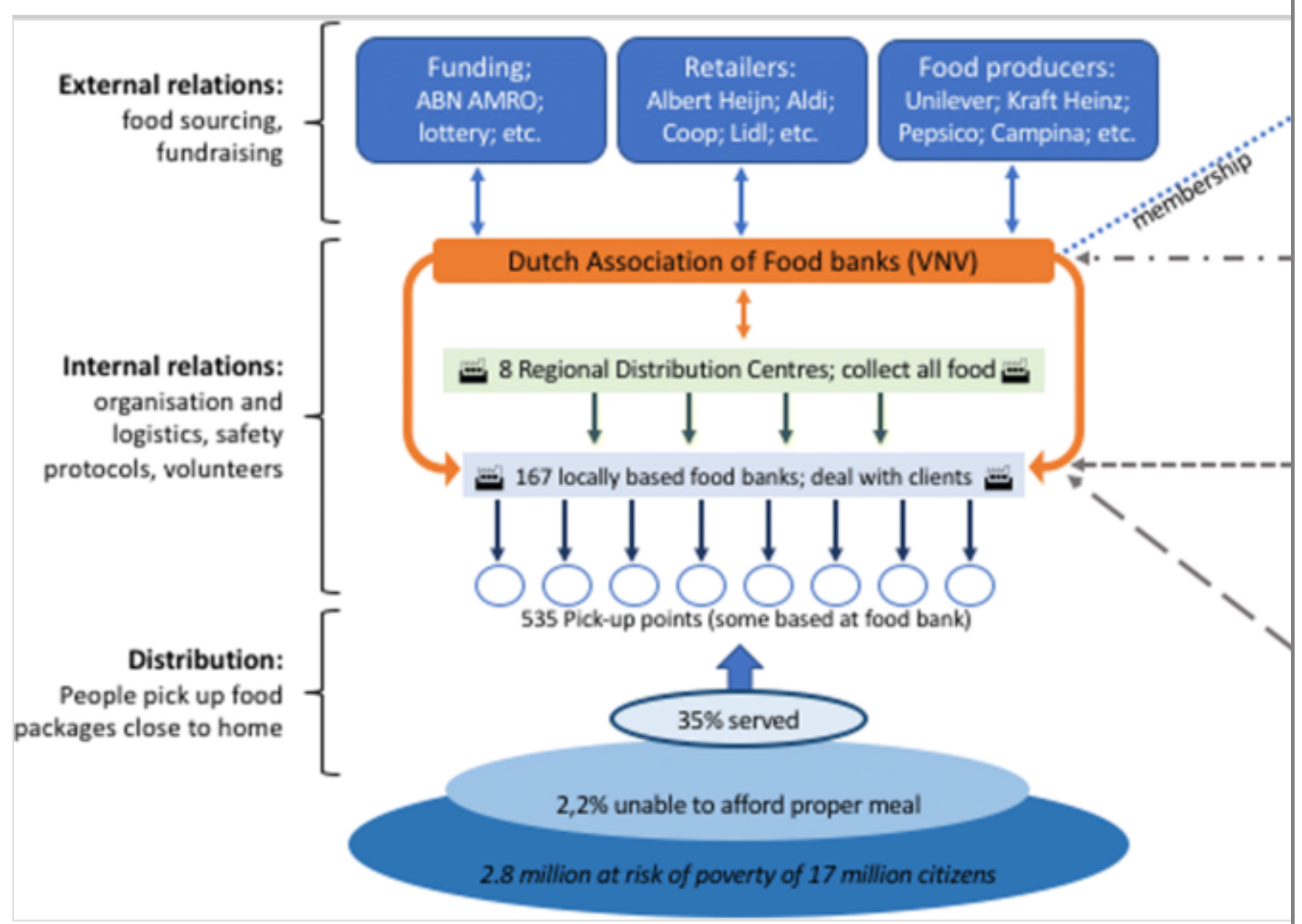

Fig. 4

Food assistance functions, actors, internal and external relations in Ireland 


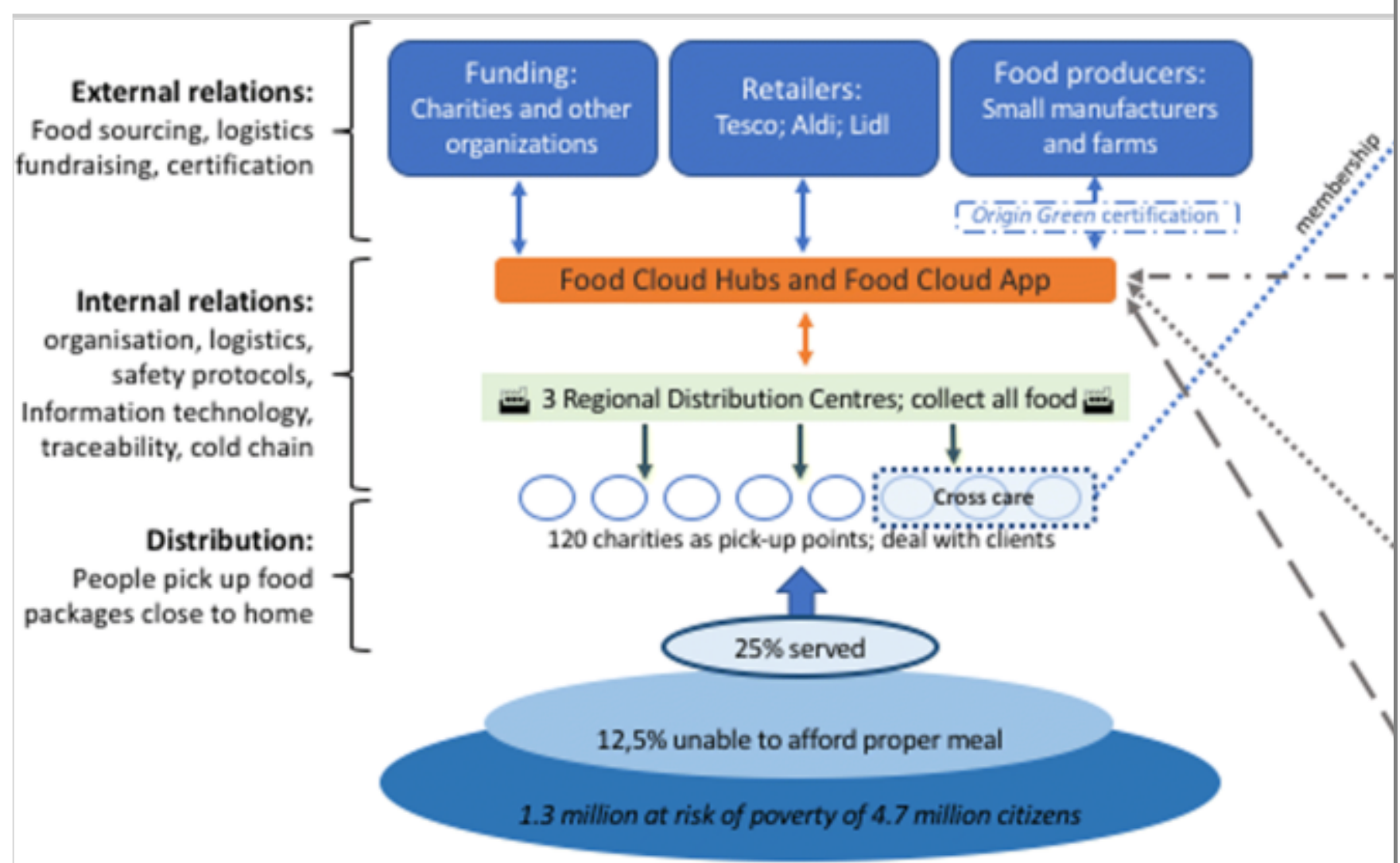

\subsection{Food assistance in Italy ${ }^{6}$}

Food assistance provision in Italy is carried out by non-profit and social organisations, which are often voluntary and/or faith-based. The food assistance system entails first and second level organisations: second level charities collecting and re-distributing free foodstuffs to first level charitable organisations which directly assist those in need (Baglioni et al. 2017; Rovati and Campiglio 2009). The latter distribute free foodstuffs, mainly in the form of regular support (food parcels, charity shops) and provide meals (on the road, in canteens or in residential communities). The Italian Food Bank Foundation (FBAO, Fondazione Banco Alimentare Onlus) works according to a warehouse model, allowing it to save large quantities of food otherwise destined for waste streams. It is a nonprofit organisation that since the late 1980s takes care of the daily recovery of edible food and its redistribution through other charities (Santini and Cavicchi 2014). The first food bank in Italy was established in 1989, thanks to an encounter between Danilo Fossati, head of the Star food company, and Father Luigi Giussani, founder of the Communion and Liberation movement. Following the example set by the Fondacion Banco de Alimentos in Barcelona, and inspired by its originality, Fossati and Giussani started to promote this charitable activity together, under the motto "An organisation made of people, working for people". 
According to Eurostat (2015), there are 17.4 million citizens in danger of poverty and social exclusion (around $29 \%$ of the population) in Italy, of which $12 \%$ are unable to afford a proper meal. In 2016, food banks distributed food to roughly $22 \%$ of the "food poor". It is safe to assume that there are more households which are unable to afford a proper meal than are currently reached by the food bank. Figure 3 represents the multiple relations that link the main actors of food assistance in Italy. The fragmentation and local specificity of relations, together with the informal nature of services, makes it a synthesis of the entities involved in food poverty assistance.

The governance of food assistance in Italy includes twenty-one regional food banks, territorial organisations which are constituent members of the FBAO (which guides and coordinates their activities). The regional food banks establish links and coordinate relationships with food producers, and larger and smaller retailers, for food surplus collection and storage. A large number of non-profit charitable organisations are on the frontline, in direct contact with recipients. These charities periodically turn to their local regional food bank to source large quantities of food products, based on a permanent agreement that allows them to trace and thus adhere to food safety and hygiene requirements.

Front-line actors are widely spread out on territories and are both of religious and secular origin. Among the most popular in Italy, Caritas, is a body set up by the Catholic Church to serve the poor and to promote charity and justice throughout the world (i.e. advocacy), and is organised at local (parish), diocesan, national, regional and international level (i.e. the Caritas Internationalis Confederation).

Food assistance practices range from food parcel distribution (when recipients own a kitchen for cooking), to ready meals either delivered by mobile units and by soup kitchens placed in fixed locations. Food and drink is also delivered to those who live on the streets, together with clothing and other types of assistance. Food vouchers are distributed to allow access to conventional, affiliated shops. "Emporia of Solidarity", promoted by Caritas represent an emerging form of food assistance: they look like small supermarkets but are accessible with electronic cards which are pre-loaded with a certain number of points (assigned by the charitable organisation, based on a suitable income indicator). Emporia also offer non-food related supplementary services (Tomei and Caterino 2013).

The need to adapt food assistance practices is well captured by the words of one of the Caritas Directors interviewed: 
"When the first Caritas started this service in the 70s, people seeking assistance were a few, marginalized people and the food parcel was a significant help. Now we meet a wider segment of the population - it has more than tripled in the last years - people who had a job until yesterday and are used to taking care of themselves and making their own food choices. So, food parcels are no longer an appropriate service, it is the users themselves who say so" (Caritas Director, Personal communication 2015).

In terms of provisioning, a significant share of food recovered by the regional food banks derives from the Colletta Alimentare (Food Collection) food drive. The annual national event represents the moment of greatest visibility of the food bank: every year in November, throughout Italy, thousands of volunteers go to outlets of large retailers asking citizens to donate products to the recipients. Caritas, food banks and other appointed organisations receive another consistent share of the food resources through AGEA (The National Agency for payments in Agriculture), the national agency that collects and distributes food being transferred from the EU fund FEAD. In quantitative terms, European FEAD funds represent the first source of supply for food banks. FEAD resources consist of distributions of food products purchased by AGEA, with a subsequent transfer to partner organisations.

The multiple connections among all actors are extremely context specific, and overall the food assistance system is rather flexible and widespread. However lack of coordination and contrasts also emerge, as expressed by the words of a regional food bank director:

Sometimes it happens that difficulties related to specific personalities arise in some territories. Take the food drive, for example: in terms of volunteers, we rely on local associations, which sometimes contest the ways of collecting and redistributing food by the food bank. Therefore, they go directly to the retailers, who simultaneously engage with them and the food bank, causing overlapping and competition among initiatives.

(Regional food bank, Personal communication, 2015)

An essential institutional element of food assistance provisioning is the Good Samaritan Law (Law n. 155, July 2003). The State enacted this single-article law which equates voluntary non-profit organisations collecting and redistributing surplus food to the poor to a normal consumer transaction. ${ }^{7}$ With the passing of this law, responsibility for food safety shifted to charitable organisations, at least 
in relation to transportation and storage, thus simplifying donation procedures for private firms. Consequently, many food recovery practices have been triggered by the Good Samaritan Law. In 2016, the Italian Parliament passed a law on waste reduction by facilitating and incentivizing easier and more homogeneous food recovery procedures, integrating the Good Samaritan Law by providing incentives to private firms in order to further encourage donations. Processors and retailers get involved in different ways in food collections and surplus food donation to non-profit and charitable organisations. In some cases, farmers also get involved in surplus food recovery and redistribution.

Regarding institutional relations, both the FBAO and Caritas (among other national level organisations) play a key role in terms of advocacy. Caritas Italiana addresses the limitations of the Italian government to steer intervention towards poverty reduction, by emphasising that Italy is the only European country, along with Greece, without a national measure aimed at supporting the population living in absolute poverty (i.e., unemployment subsidy ${ }^{8}$ ). In addition, current public interventions for poverty mitigation are deemed inadequate based on decreasing dedicated economic resources, which are dispersed across a set of uncoordinated measures. Finally, most of the public funding available consists of financial contributions, while "person dedicated services", which are led by Municipalities and the third sector, are underfunded (Caritas Italiana 2015).

\subsection{Food assistance in the Netherlands ${ }^{9}$}

Food banks were first established in the Netherlands in 2002. This was the initiative of a Dutch family living in Rotterdam, who decided to start a food assistance project for a small group of people in their area that was experiencing financial trouble. Driven partly by their Christian faith and inspired by a food bank which had started in Belgium in 1994, they started as a small-scale operation from their house. In less than a decade, the number of food banks grew rapidly. Currently, the Dutch food bank is comprised of a headquarters operating at the national level and, connected to that, many community-based food banks (see Fig. 4). Governance of the food banks is via an umbrella structure, uniting all foodbanks under the Vereniging Nederlandse Voedselbanken (VNV, translates to Association of Dutch Food Banks). In 2015, 167 food banks were registered to the VNV distributing food assistance through 535 distribution points spread across the Netherlands (VNV 2016). The VNV serves as an umbrella organisation that takes more general tasks out of the hands of local food banks and contributes to its two main objectives: offering direct food assistance to those most in need, and preventing the waste of good food, under the motto "citizens for citizens". 
In the Netherlands, we had built a social system that made everybody think: 'everybody can purchase food, so direct food assistance is not necessary, as it was formerly'. The second big development, which runs parallel to that, is the secularization and separation of church and state. Because of this, help in kind disappeared. These two developments caused a 'gap in the market'. Apparently, there were still people suffering from hunger, reasonably invisible to the eye of the general public. Out of this observation the first food bank was started, on a very small scale (VNV, Personal communication,

AQ11

2016 2015).

According to Eurostat (2015), there are 2.8 million Dutch citizens at risk of poverty and social exclusion (around $16.5 \%$ of the population), and $2.2 \%$ unable to afford a proper meal. In 2016, Dutch food banks have reached approximately 135,000 people, ensuring them food for three days per week, representing roughly $35 \%$ of the "food poor". Eligibility for food assistance is determined via an income indicator: "household allowance" (i.e. "leefgeld"), which corresponds to the amount of money a household has left to spend after deducting all fixed costs such as housing costs and electricity. A household can appeal for a food package when the 'leefgeld' is lower than the amount specified for the composition of the household. For example, for a household with a single adult and one child this amount is $€ 250$.

The VNV deals with processes that are relevant to all food banks such as institutional connections and food sourcing. Moreover, it aims at standardizing operations, for example by setting indicative admission thresholds common to all food banks (agreed upon after a voting session). Locally-based food banks have an equal say in national-level decisions thanks to the umbrella organisational structure. Simultaneously, it keeps common rules open for local interpretation, so that all the different food bank "cultures" can work with it in an adaptive way, given their particular needs, challenges and available resources. This leads to two main advantages: firstly, food banks have a rather flexible governance model; secondly, instead of depending on a geographical allocation of food, it is now distributed equitably over food banks. The structure of the VNV is highly professional as most of the volunteers working at the VNV are retired professionals. One of the future aims of the VNV is to professionalize even further and create more efficiency in food sourcing and food safety by, amongst other things, focussing on finding new skilled board members. 
In terms of relations with recipients, there are various different institutions that can refer people to food banks. Most common is an appeal for food assistance after this suggestion is made by a social worker. Others may be directed to the food bank by their local church or municipality. The VNV requires that a food bank recipient should always interact with and be supported by a social worker, as the food parcel is meant to be a non-permanent form of relief, and must be complemented by other interventions. Overall, food banks contribute to more flexible and contextual targeting of food poor, despite it being only a fraction of the vulnerable. The targeted include mostly single-parent households and immigrants, who often are unable to access and therefore do not make use of or the complete range of available welfare resources. According to the VNV, this is because of (digital) bureaucratic processes that prove too complex or incomprehensible (VNV, Personal communication, 2015).

Turning to institutional relations, one of the main tasks of the VNV is to interact with the government and larger food industries on behalf of all the local food banks. At EU level, the VNV is also connected to the European Federation of Food Banks (FEBA) where they collectively try to push the food banks' agenda. Interestingly, one of the main points of the VNV is that they stay 'a-political' in these processes.

As a food bank, we don't have an opinion on [policy].... We are neutral. If the government feels that they, for whatever reason, have to retreat and leave things to the market, then that is a political discussion and those are political choices.

(VNV, Personal Communication, 2015)

The Dutch government has not been supportive of policy that provides for direct food assistance or help in kind since 1995, while supporting social policies that combat poverty and promote social inclusion (Timmermans, 2012). The type of assistance the food bank provides is neither supported by any social policy nor is it on the political agenda. While overall food banks do not receive financial or structural help, local governments often aid food banks, for example by offering them rent-free municipal-owned spaces or the use of a van for the transporation of food (Stimulanz and Ministry of Social Affairs and Employment 2009).

[The government] told [us]: 'Direct food assistance does not exist in the Netherlands and as a government we will certainly not participate in it. ... It is a private initiative. It's great that you are doing it, but we will not meddle with it.' That was made quite clear to us. We bring matters under discussion by deliberating 
through different channels. We maintain our contacts with the private sector; we keep in touch with members of the government and the officials surrounding them. By doing exactly that, we prevent being pulled into public and political debates.

(VNV, Personal communication, 2015)

Despite the government's continued denial of the food bank's role, it simultaneously provides de facto recognition of their contribution. Indirectly and unofficially, various ministers and secretaries of state have supported food banks by attempting to find "loopholes" in, for example, food safety laws (i.e., ways for the food bank to still be able to redistribute food fit for consumption, while sticking within the law). Concerning other external relations, VNV has a prime role in establishing stable linkages with actors in the food industry, retailers and private donors. Since VNV has taken up this responsibility more food is being sourced and re-distributed in a fairer way across food banks' geographical locations.

"Now things run in a much more streamlined way. Before, everybody had their own kingdom. Now the VNV is taking care of sourcing food from the national players, it's much fairer. Before food would 'stick' to certain regions where they might not even have needed it so badly.

(Eindhoven food bank, Personal communication 2015)

These relations with food industry are actively sought out by the food bank, persuading many food sector actors to donate their surplus foods by "offering a win-win situation" (Personal communication with VNV, 2015), the wins being for both food banks and industry: while the first receives food donations, the latter has financial gains by saving the costs associated with food waste and in having an improved corporate socially responsible image. Business-partner agreements are slowly becoming more important with regard to the diversity of foods, for example since a deal with a large nationally operating cooperative dairy processor, dairy products can now be guaranteed to be in the food packages. By further pursuing food safety certification, the VNV seeks to guarantee for large food industry actors that the food banks will handle their surplus foods in a secure way, safeguarding against issues of liability.

\subsection{Food assistance in Ireland ${ }^{10}$}

Food assistance initiatives (including food banks and redistribution initiatives) are growing in number in Ireland and form a key part of the food poverty 
interventions underway. Ireland's first and only (for many years) food bank was the Dublin Food Bank. It was established in 1989 by Crosscare, a charity which is allied to the Dublin Catholic Diocese (crosscare.ie). In recent years, similar organisations have been established around the country. However, most of these initiatives are too small in scale to have the infrastructural capacity to process large quantities of surplus food; this means that much of the 50,000 annual tonnes of the Irish food sector's surplus was, until recently, being wasted ( www.food.cloud.com , 2015). In response to this, Food Cloud Hubs (FCH), ${ }^{11}$ when in nascent form, successfully applied for a grant from Ireland's Environmental Protection Agency (2011) to conduct a feasibility study on how this surplus food could be redirected to those in food poverty. The findings of this study supported the establishment of FCH the following year, its objective being to mediate between food businesses and charitable organisations which provide those in need with food aid.

The recent worldwide financial crisis of the late 2000s impacted heavily on unemployment levels, poverty rates and the state of public finances in Ireland (Bergin et al. 2011) and led to a series of austerity budgets before the economy gradually began to recover. It is against this backdrop that efforts to alleviate food poverty emanated mainly from grassroots organisations, with top-down programmes and strategies largely failing to address this issue. Approximately 1 in 8 people (or $13 \%$ of the population) in Ireland currently experience food poverty, as do even more (up to $23 \%$ ) among vulnerable sectors of society such as low-income households, those who are unemployed, the disabled, lone parent families and children (Department of Social Protection, 2015). Initiatives to provide food assistance are becoming more common in Ireland and are fundamental in efforts to tackle food poverty. Figure 4 represents the relations that link the main actors of food assistance in Ireland.

Key capacities of FCH are its use of logistical solutions, and information and communication technologies. Alleviating the environmental costs of food waste is an important goal and FCH tracks the embedded carbon savings made through the diversion of food from waste to redistribution streams. This organisation positions itself as providing a much needed service for busy businesses and charities.

For us, when we get a product from a supplier with a life code that is too short, it is too expensive to back haul it. Food Cloud Hubs are able to take large scale donations from us and dole it out to charities. As a result we have much less food going to reprocessing sites. We will always have food waste so this has given us a fantastic opportunity to for its redistribution. 
(CSR officer large multi-national retailer, Personal communication, 2016)

This initiative also advocates for policies to support processes which relate to the redistribution of surplus food, for example food donation laws which limit donors' liability. This would be similar to 'Good Samaritan' laws already enacted in a number of US states and would, it is hoped, make food businesses more likely to engage with FCHs (Morenoff 2002).

There's a commercial sensitivity where food companies are afraid of their brand reputation being sullied if their food is not being handled properly. They're afraid there might be a claim against them. We need to allay these fears. For this reason we had to invest in an IT system to track every morsel of food. Also we explicitly take responsibility for the next part of the chain. Similarly, we take responsibility downstream so that charities are not responsible. That was major stumbling block initially so we've done some work around lobbying for statutory protection for those who give something in good faith.

(FCH steering group member, Personal communication, 2016)

The 'Hubs' of Food Cloud Hubs are based strategically in Dublin, Cork and Galway, Ireland's first, second and fourth largest cities respectively. Surplus food, much of which is channelled through the Dublin base, is delivered to these hubs before being organised for delivery to or collection by client charities. Food businesses (manufacturers, retailers) make contact with their local $\mathrm{FCH}$, providing details of their current food surpluses. FCH currently has 'businesspartner' arrangements with Tesco Ireland, Aldi Ireland and Lidl Ireland, meaning $63 \%$ of Ireland's grocery market direct surplus food through FCH ( www.kantarworldpanel.com , 2017). In addition, almost 100 Irish food manufacturers are engaging with the initiative in some way, ensuring a stable source of food. Using information and communications technologies, the logistics of redistributing donated surplus food match professional industrial standards. Recipient charities can then easily log on to FCH's online system to view which food is in stock and place orders according to their clients' needs and preferences.

I get an email from them at the beginning of the week which is very specific on what's available. I don't take everything. I look at the people we have; if you get a load of curries there probably wouldn't be that much demand because when people have 
addictions their stomachs aren't able for spicy food. I specifically look for chicken, meat, fresh vegetables and butter if they have it. I get some of this each week and it makes a big difference.

(Addiction treatment facility, Personal communication, 2016)

FCH is governed by its board, which is comprised of individuals from a range of backgrounds. This includes a number of retirees who bring skills and experiences from areas of business which are relevant to FCH's operations. Each depot is staffed by paid employees as well as some volunteers. The initiative receives little direct national governmental support, perhaps due to its goals and functions falling 'between stools' of three ministry's briefs: the Department of Employment Affairs and Social Protection; the Department of Communications, Climate Action and Environment; and the Department of Agriculture, Food and the Marine. Local government and semi-state bodies have provided support, both financial and otherwise. At its inception, Cork County Council provided FCH with $€ 20,000$ per year for five years. The National Treasury Management Agency has provided funding through its Dormant Accounts Fund. Ireland's food board, Bord Bia, promotes engagement with FCH to applicants to its Origin Green programme ${ }^{12}$ which includes a significant proportion of all retailers and manufacturers in Ireland. At European Union level, this initiative is facilitated in its aims through the Fund for the European Aid for the Most Deprived (FEAD). ${ }^{13}$ In the most recent round of the FEAD programme (2014-2020), FCH was designated as Ireland's partner organisation for the food element of the programme.

The key strength of FCH is that it is a novel and important response to food insecurity in Ireland, providing a streamlined infrastructural solution to the problem of redistributing large volumes of surplus food. Although it works to reduce the negative environmental outcomes of food waste, it does little to address processes which cause such high volumes of food surplus and which necessitate food aid. In fact, despite an express aim of FCH being to challenge the 'underlying social causes of hunger', stakeholders admitted the initiative was hesitant to probe too deeply into the structural causes of food poverty. This was in anticipation of Government and private sector interests being less likely to become involved due to fears that 'engaging is admitting': showing support for FCH would only highlight the problems they have a hand in causing or should take more responsibility in solving. Nonetheless, $\mathrm{FCH}$ pragmatically provides an essential service for charities which reduces the burdens they face to provide basic nourishment for their clients and allows them to channel more of their scarce resources into tackling causes of food poverty. 


\section{The role of food assistance systems in addressing food poverty}

The three food assistance cases have been analysed in their development and mapped to show what functions they perform, what processes they tap into, what actors they associate with and what resources they use. The different time frames, historical development and contexts have led to different approaches to the initiatives in the three countries. The set-up of the governance models has taken place at different times, with the Italian case having been established in the late 1980s, followed by the Dutch case at the beginning of the millennium, and the Irish case in 2012. Because the three initiatives find their origin in different times, they have been shaped by different governing structures and different available resources. Nevertheless, we see a pattern of different levels of actors within the food assistance initiatives across the countries, leading to a characterisation of food assistance systems (see Fig. 5).

\section{Fig. 5}

The main elements (actors, resources, processes and functions) of food assistance systems across the three cases 


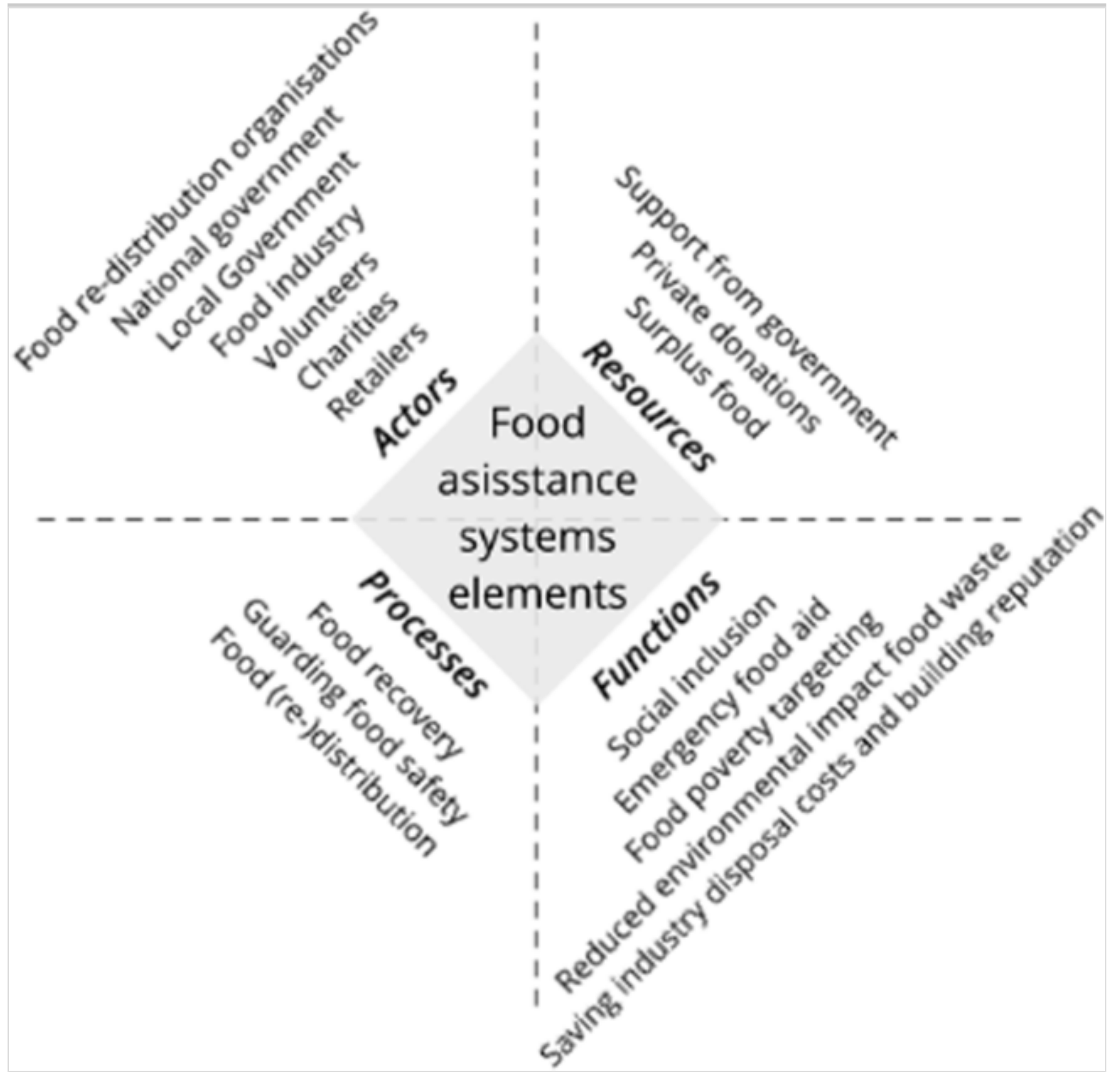

They all feature front line actors, who are in direct contact with the multidimensionality of poverty, and secondary actors that support them with food and resource management. The front line charitable organisations act on an urgent need: by identifying it and, to the extent that this need concerns food, develop and respond with a range of food assistance practices. This response is tailored to address recipients' requirements (i.e., food redistribution or meal services). In all cases, this has led to the foundation of a secondary organisation that supports front line actors by providing coordination, handling of surplus food donation, logistics and storage and financial support. As shown, surplus food redistribution organisations have been established to raise material and monetary donations from individual contributors, public administrations, and companies; they manage, collect and distribute these contributions to charities that deliver food or prepare meals. These exchanges take place locally, often in interaction with food system actors and policy makers. 
The systems perspective to food assistance initiatives has led us to the adoption of a novel analytical framework for understanding their governance. The concept of "boundary spanning" governance - detailed in the next sub-section - allows for a nuanced interpretation of the governance dynamics involved in food assistance initiatives.

\subsection{Food assistance initiatives as active 'boundary spanners'}

Food assistance initiatives work primarily to provide emergency relief to an urgent situation of need. However, in the three observed cases, we see evidence of intiatives going beyond this. This can be explained by two developments. First is their position at the interface of the food, welfare and third sector systems, making food assistance a hybrid system. Being at this interface leads to connections to many different actors, the performance of a wider range of activities, and their being affected by a number of drivers that are found in other systems. Striving to deliver emergency relief effectively, the initiatives are compelled to address the multidimensionality of food poverty and the various food system activities connected to the logistics of food.

The second key development, and embedded in the multidimensional approach to poverty, is what others have described as 'ethical sense making' (Elmes et al., 2013): food assistance initiatives have started reflecting on the ethical implications of only offering emergency food assistance. In the case studies this has extended to considerations of the environmental consequences of waste as well as realising that the activity of emergency food poverty relief functions as an entry point to reach vulnerable people. For the latter, this offers the potential to assess and combat poverty, and trigger pathways of social inclusion (Nussbaum 1997; Sen 1985; Maslow 1942). This view allows food assistance initiatives to "mak[e] the connections between physical health, mental health and social care needs" (Bickerstaffe 2013). This is emphasised in the initiatives now attempting to going beyond food assistance and experimenting with other opportunities to indirectly deal with food poverty, for example by better targeting of the (food) poor and improving the targeting of social welfare.

The involvement of citizens, food industry actors, and policy makers has become more pervasive in food assistance. Building further on the collaborative governance literature, we argue that food assistance initiatives can be considered "boundary spanners". Also described as 'change agents', it has been argued that these actors are needed to "make the connection between societal developments at the landscape level, putting pressure on the dominant regime and creating room for manoeuvre at the local level" (Hassink et al. 2013; Roep et al. 2003 
p.212). They contribute by building trust in situations where "the actors and areas of activity involved are distant from each other" (Durrant 2014 p. 80).

We observe that all three initiatives are forms of collaborative governance, where the food assistance intiatives often act as boundary spanners in attempts to create new connections, by spanning 'physical', 'cognitive', or 'social' boundaries (Termeer and Bruinsma 2016). Boundaries may be physical, involving the creation of physical spaces for meetings that belong to public institutions but are given for use to charitable initiatives. Other examples of spanning of physical boundaries are the overcoming of technological or spatial barriers, through the use of e.g. software, web applications that allow actors of the three systems to actively interact by making the connections between food processors and retailers. The latter being highlighted in the Irish case, where ICT allowed for easier allocation of a supply of surplus food and demand for food in food assistance intiatives. But barriers can also be cognitive in nature, in the sense that they hinder a mutual understanding and create differences in knowledge, language or meanings. All food assistance actors worked with policy makers to overcome relevant food health and safety legislative barriers, in effect redefining the meaning of 'food waste'. In Italy, a participatory process led to the creation of an "Alliance for Food" aimed at setting up a common vision on governance of food assistance, education processes all aimed at an a "person centered approach" (see Galli et al. 2016). Lastly, food assistance initiatives show evidence of spanning social boundaries, in the sense that they contribute to social capital, which "includes connections among people based on norms of reciprocity and mutual trust" (Termeer and Bruinsma 2016 p. 92). This is evident for example in the Italian case, where the national food drive day has a public resonance as it is aimed at steering private citizens' engagement in donating part of their shopping in order to "share needs to share the meaning of life". In a different setting, the Dutch food bank finds its place in society, but by emphasising their civil society origin. As it is against their interests to take a highly political standpoint, they prefer to stress their voluntary nature and provide space within their initiative for other Dutch citizens organisations (such as sport clubs) to carry out one-off good deeds by collecting money or food.

\subsection{Key challenges for food assistance initiatives}

Although this analysis has highlighted a range of benefits of the 'boundary spanning' nature of the case study initiatives, it has also revealed that a systemic solution to the systemic problem of food poverty remains elusive. Our analysis reveals two topics related to food assistance systems as particularly urgent; if these are addressed, responses to food poverty may evolve to be more sustainable and more ethically acceptable. 


\subsection{Operational challenges}

Food assistance initiatives face the organisational challenge of handling food surplus management and logistics, and the redistribution of that surplus food while in the meantime taking care of tailoring assistance to the recipient's needs. In the case of Ireland, this has led to the genesis of 'Food Cloud', an online platform to speed up such interactions between food industry, secondary organisations and the front-line charities. As such, surplus food's expiration date offers a continuous short-term challenge, which alone requires the majority of the initiatives' attention, rather than systemic food poverty alleviation that addresses root causes.

On top of that, initiatives point out that the biggest challenges lie in meeting the requested needs, feeling at times their inadequacy, as stated by some of the charities' reports (Caritas Tuscany Report, 2015). In the Irish case, the challenge stems mainly from financial limitations which impact on operations. Such inadequacy may signify a lack of food or structures (resources, volunteers) at certain times of the year, or, on the opposite side, an overabundance of surplus food, to be managed at other times of the year. Food bank leaders are conscious of the sometimes modest nutritional value of the food parcels (Neter et al., 2014). Some attempts have been made to improve this by diversifying the food products available: in some of the Italian intitiatives we see charitable food assistance coupled to training in financial management and awareness-raising on nutritionally balanced diets. In the Netherlands we see attempts to establish connections and collaborations with local urban agriculture.

Despite these innovative solutions, it is only a measure to help those in immediate and urgent need. It is difficult for food assistance systems as they are currently shaped, to have a major impact on systemic food poverty reduction.

\subsection{Food waste 'reframing': Ethical considerations}

All three cases are playing a growing role in dealing with a large portion of what was previously destined to be food 'waste'. Food assistance initiatives have therefore contributed to the reshaping of the meaning of 'food waste' and the facilitation of a 'surplus food chain' that benefits those who are living in food poverty, in the short-term.

While seemingly positive, this has the potential for competition for surplus food between food assistance intiatives and social enterprises which use these foods to create and market new processed foods (e.g. soups or sauces). The increased demand for surplus food will almost certainly lead to unfair competition, as a company is able to pay for surplus foods, while a food bank is not. This begs the 
questions: what foods will be left of those surplus streams for food assistance initiatives?; and is it ethically acceptable to expect the poor to live off these foods?

Departing from the same point, there may be a potential future dilemma between the dependency of people in need on surplus food streams, and moves by food businesses to reduce their environmental impact by streamlining systems to reduce the amount of food which becomes "surplus". Food industries and retail stand to not only reduce their environmental impact, but also to save money and to gain reputational benefits if they decrease the amount of food they 'waste', which is more likely as technologies around, for example, food processing and logistics progress.

If root causes for food poverty are not addressed in the near future, leading to an increase in food poverty, food assistance initatives will not be able to provide enough food. This challenge is inherent in food assistance, as it aims to address an immediate and urgent need for food. The often stated question of whether it is ethical to leave such a difficult task to the hands of voluntary initiatives (See e.g. Lambie-Mumford et al. 2014; Riches and Silvasti 2014; Dowler and O'connor 2012) further emphasises the need to critically reflect on the dynamics that underly food poverty and how these can be best addressed.

\section{Conclusion}

Understanding the modes of governance within food assistance initiatives is crucial, as they have become increasingly institutionalised in addressing food poverty, in its multiple forms. Situated in, and intertwined with social welfare, food and third sector systems, they attempt to make connections that deal with the multidimensionality of food poverty. As such, the objective of this paper was to further insights into the modes of governance that characterise food assistance initiatives, based on three empirical cases of food assistance initiatives that redistribute surplus food to those who experience food poverty. The analysis was structured by taking a systems perspective in the identification and mapping of food assistance elements (i.e., structures (actors, resources), functions and processes). This allowed us to visualise and understand similarities and differences in food assistance governance models and collaborative forms of governance taking place. It also showed how food assistance governance models have been shaped by the governing structures around them and resources available, in terms of scale and scope.

Through the adoption of a systems perspective, we distill a number of opportunities for improvement related to food assistance governance and serving 
those that are hungry now. The first opportunity being that food assistance initiatives go beyond mere emergency food poverty relief. This finds its origin in being at the interface of food-- welfare- and third sector systems and food banks' 'ethical sense making'. Connected to this, we see food banks' active boundary spanning activities as an opportunity, especially when many states move towards more de-centralised and neo-liberal governance systems. Nevertheless, the inability of food assistance to address root causes, leads to some unavoidable points for reflection that need to be addressed: the first being their need to balance the short-term goal of distributing surplus foods, with the long-term goal of food poverty reduction. Both are urgent, but the first with a more short term solution, leaves the second exposed and in some cases ignored; the second, and reflecting on the ethics of these developments, is whether food banks' succesful reframing of food waste will lead to a deepening of people's marginalized positions.

Food assistance initiatives are a civil-society initiated response to serious multidimensional problems, both shaped by and complementing the social welfare and food systems in which they are embedded. However, our discussion shows that while they have managed to find innovative and collaborative governance solutions to address the very immediate issues rather effectively, they do not negate the need for food system transformation to address the ultimate reasons of poverty.

\section{Acknowledgements}

This research is part of the project "Assessment of the impact of global drivers of change on Europe's food security" (TRANSMANGO), granted by the EU under 7th Framework Programme, theme KBBE.2013.2.5-01, Grant agreement no: 613532 .

\section{Compliance with ethical standards}

Conflict of interest The authors declare that they have no conflict of interest.

\section{References}

\section{AQ12}

ACOSS. (2011). The emergency relief handbook: Guide for emergency relief workers (4th ed.). Strawberry Hills: Australian Council of Social Service.

Arcuri, S., Brunori, G., \& Galli, F. (2017). Insights on the role of private and public actors in food assistance provision: A literature review for high income 
countries. Economia Agro-Alimentare., 119-150.

https://doi.org/10.3280/ECAG2017-001006 .

Arcuri, Sabrina, Francesca Galli, and Gianluca Brunori. (2016) "Local” Level analysis of FNS pathways in Italy: Food assistance in Tuscany.

TRANSMANGO: EU KBBE.2013.2.5-01 Grant agreement no: 613532.

Available here:

https://www.researchgate.net/publication/309196346_LOCAL_LEVEL_ANALYSI THE_CASE_OF_FOOD_ASSISTANCE_IN_TUSCANY

Baglioni, S., De Pieri, B., \& Tallarico, T. (2017). Surplus food recovery and food aid: The pivotal role of non-profit organisations. Insights from Italy and Germany. VOLUNTAS: International Journal of Voluntary and Non-profit Organisations, 28(5), 2032-2052.

Bergin, A., Gerald, J. F., Kearney, I., \& O'Sullivan, C. (2011). The Irish fiscal crisis. National Institute Economic Review, 217(1), R47-R59.

Bickerstaffe, S. (2013) Towards whole-person care. Institute for Public Policy Research:

http://www.ippr.org/files/images/media/files/publication/2013/11/wholepersoncare_Dec2013_11518.pdf?noredirect $=1$

Biebricher, T. (2015). Neoliberalism and democracy. Constellations, 22(2), 255-266.

Booth, S., \& Whelan, J. (2014). Hungry for change: The food banking industry in Australia. British Food Journal, 116(9), 1392-1404. https://doi.org/10.1108/bfj-01-2014-0037 .

Brunori, G., Malandrin, V., \& Rossi, A. (2013). Trade-off or convergence? The role of food security in the evolution of food discourse in Italy. Journal of Rural Studies, 29, 19-29.

Brunori, G., Bartolini, F., Avermaete, T., Mathjis, E., Brzezina, N., Moragues Faus, A., Sonnino, R. and Marsden, T (2015) D2.1. Conceptual Framework. Assessment of the impact of global drivers of change on Europe's food and nutrition security (FNS). KBBE.2013.2.5-01. TRANSMANGO FP7. Summary available here: http://www.transmango.eu/userfiles/file/transmango $\% 20$ conceptual $\% 20$ framework (accessed on 22 October 2018) 
Burns, C., Jones, S. J., \& Frongillo, E. A. (2010). Poverty, household food insecurity and obesity in children. In Preventing childhood obesity: Evidence policy and practice (pp. 129-137).

Candel, J. J. (2014). Food security governance: A systematic literature review. Food Security, 6(4), 585-601.

Candel, J. J., \& Pereira, L. (2017). Towards integrated food policy: Main challenges and steps ahead. Environmental Science \& Policy, 73, 89-92.

Caraher, M. (2015). The European Union food distribution programme for the Most deprived persons of the community, 1987-2013: From agricultural policy to social inclusion policy? Health Policy, 119(7), 932-940.

Caraher, M., \& Cavicchi, A. (2014). Old crises on new plates or old plates for a new crises? Food banks and food insecurity. British Food Journal, 116(9). https://doi.org/10.1108/bfj-08-2014-0285 .

Caritas Italiana (2015) Dopo la crisi costruire il Welfare. Rapporto 2015. Link http://s2ew.caritasitaliana.it/materiali/Pubblicazioni/libri_2015/Rapporto_politiche (accessed on 20.12.17).

Carroll, Brídín, and Deirdre O'Connor. (2016) "Local” Level Analysis of FNS Pathways in Ireland. Exploring Two Case Studies: Cork Food Policy Council and Bia Food Initiative. TRANSMANGO: EU KBBE.2013.2.5-01 Grant agreement no: 613532 .

Clapp, J. (2016). Food (2nd ed.). Cambridge: Polity Press.

Clark, W. C., Tomich, T. P., Van Noordwijk, M., Guston, D., Catacutan, D., Dickson, N. M., \& McNie, E. (2016). Boundary work for sustainable development: Natural resource management at the consultative group on international agricultural research (CGIAR). Proceedings of the National Academy of Sciences, 113(17), 4615-4622.

Cordell, D., Drangert, J. O., \& White, S. (2009). The story of phosphorus: Global food security and food for thought. Global Environmental Change, 19(2), 292-305.

Daponte, B. O., \& Bade, S. L. (2000). The evolution, cost, and operation of the private food assistance network. Institute for Research on poverty. In University of Wisconsin-Madison. 
Dowler, E., \& O'connor, D. (2012). Rights-based approaches to addressing food poverty and food insecurity in Ireland and the United Kingdom. Social Science and Medicine, 74(1), 44-52.

Duncan, J. (2015a). " Greening" global food governance. Canadian Food Studies/La Revue canadienne des études sur l'alimentation, 2(2), 335-344.

Duncan, J. (2015b). Global food security governance: Civil society engagement in the reformed committee on world food security. Routledge.

Durrant, R. A. (2014). Civil society roles in transition: Towards sustainable food? SPRU - Science and Technology Policy Research University.

Elmes, M. B., Mendoza-Abarca, K., \& Hersh, R. (2016). Food banking, ethical Sensemaking, and social innovation in an era of growing hunger in the United States. Journal of Management Inquiry, 25(2), 122-138. https://doi.org/10.1177/1056492615589651 .

Emerson, K., Nabatchi, T., \& Balogh, S. (2012). An integrative framework for collaborative governance. Journal of Public Administration Research and Theory, 22(1), 1-29.

Ericksen, P., Stewart, B., Dixon, J., Barling, D., Loring, P., Anderson, M., \& Ingram, J. (2010). The value of a food system approach. Food security and global environmental change, 25, 24-25.

Ericksen, P. J. (2008). Conceptualizing food systems for global environmental change research. Global Environmental Change, 18(1), 234-245.

European Commission. (2015). Communication from the commission to the European Parliament, the council, the European economic and social eommittee and the Committee of the Regions "closing the loop - an EU action plan for the circular economy". In COM/2015/0614 final.

European Commission (2018) Summary of the annual implementation reports for the operational programmes cofinanced by the Fund for European Aid to the Most Deprived in 2015. Brussels, 28.7.2017 COM (2017) 404 final. $\mathrm{AQ13}$

Fabian Commission. (2015). Hungry for change. The final report of the Fabian Commission on Food and Poverty. Link: 
http://www.fabians.org.uk/wp-content/uploads/2015/10/Hungry-for-Changeweb-27.10.pdf

FEAD (2017) Meeting report FOURTH FEAD NETWORK MEETING: Good Practices in the Selection of Food Products 22 February 2017, Brussels. http://ec.europa.eu/social/main.jsp? catId $=89 \&$ langId $=$ en\&newsId $=2749 \&$ furtherNews=yes

Folke, C., Hahn, T., Olsson, P., \& Norberg, J. (2005). Adaptive governance of social-ecological systems. Annual Review of Environment and Resources, 30, 441-473.

Fricke, H. E., Hughes, A. G., Schober, D. J., Pinard, C. A., Bertmann, F. M. W., Smith, T. M., \& Yaroch, A. L. (2015). An examination of organizational and statewide needs to increase supplemental nutrition assistance program (SNAP) participation. Journal of hunger \& environmental nutrition, 10(2), 271-283.

Fuchs, D., Kalfagianni, A., \& Havinga, T. (2011). Actors in private food governance: The legitimacy of retail standards and multistakeholder initiatives with civil society participation. Agriculture and Human Values, $28(3), 353-367$.

Galli, F., Arcuri, S., Bartolini, F., Vervoort, J., \& Brunori, G. (2016). Exploring scenario guided pathways for food assistance in Tuscany. Biobased and. Applied Economics, 5(3), 237.

Garrone, P., Melacini, M., \& Perego, A. (2014a). Opening the black box of food waste reduction. Food Policy, 46, 129-139.

Garrone, P., Melacini, M., \& Perego, A. (2014b). Surplus food recovery and donation in Italy: The upstream process. British Food Journal, 116(9), 14601477.

George, C., \& Reed, M. G. (2017). Operationalising just sustainability: Towards a model for place-based governance. Local Environment, 22(9), $1105-1123$.

Gharajedaghi, J. (2011). Systems thinking: Managing chaos and complexity: A platform for designing business architecture. Elsevier. 
González-Torre, P. L., \& Coque, J. (2016). How is a food bank managed? Different profiles in Spain. Agriculture and Human Values, 33(1), 89-100.

Gustafson, D., Gutman, A., Leet, W., Drewnowski, A., Fanzo, J., \& Ingram, J. (2016). Seven food system metrics of sustainable nutrition security. Sustainability, 8(3), 196.

Hassink, J., Grin, J., \& Hulsink, W. (2013). Multifunctional agriculture meets health care: Applying the multi-level transition sciences perspective to care farming in the Netherlands. Sociologia Ruralis, 53(2), 223-245. https://doi.org/10.1111/j.1467-9523.2012.00579.x .

Hebinck, A., \& Page, D. (2017). Processes of participation in the development of urban food strategies: A comparative assessment of Exeter and Eindhoven. Sustainability, 9, 931.

Hebinck, Aniek, Georgina Villarreal, Henk Oostindie, and Paul Hebinck. (2015) D2.2 Transmango National Report: The Netherlands.

TRANSMANGO: EU KBBE.2013.2.5-01 Grant agreement no: 613532. http://transmango.eu/publications .

Hebinck, A., Galli, F., Arcuri, S., Carroll, B., O'connor, D., \& Oostindie, H. (2018). Capturing change in European food assistance practices: A transformative social innovation perspective. Local Environment, 23(4), 398413.

Hendriks, C. M., \& Grin, J. (2007). Contextualizing reflexive governance: The politics of Dutch transitions to sustainability. Journal of Environmental Policy \& Planning, 9(3-4), 333-350.

HLPE. (2017). Nutrition and food systems. Rome: A report by the High Level Panel of Experts on Food Security and Nutrition of the Committee on World Food Security.

Hospes, O., \& Brons, A. (2016). Food system governance: A systematic literature review. In A. Kennedy \& J. Liljeblad (Eds.), Food systems governance: Challenges for justice, equality and human rights. London and New York: Routledge.

Ingram, J. (2011). A food systems approach to researching food security and its interactions with global environmental change. Food Security, 3(4), 417431 . 
Kemp, R., Loorbach, D., \& Rotmans, J. (2007). Transition management as a model for managing processes of co-evolution towards sustainable development. International Journal of Sustainable Development and World Ecology, 14(1), 78-91. https://doi.org/10.1080/13504500709469709 .

Kim, S. (2015). Exploring the endogenous governance model for alleviating food insecurity: Comparative analysis of food Bank Systems in Korea and the USA. International Journal of Social Welfare, 24(2), 145-158.

Kneafsey, M., Owen, L., Bos, E., Broughton, K., \& Lennartsson, M. (2017). Capacity building for food justice in England: The contribution of charity-led community food initiatives. Local Environment, 22(5), 621-634.

Lambie-Mumford, H. (2017). Hungry Britain: The rise of food charity. Policy press. In Great Britain.

Lambie-Mumford, H., Dowler, E., Griffith, C., \& Caraher, M. (2014). Rising use of 'food aid'in the United Kingdom. British Food Journal, 116(9), 14181425 .

Lang, T., \& Ingram, J. (2013). Why food systems need complex governance. Addressing Tipping Points for a Precarious Future, 81.

Marsden, T. (2013). From post-productionism to reflexive governance:

Contested transitions in securing more sustainable food futures. Journal of Rural Studies, 29, 123-134.

Maslow, A. H. (1942). A theory of human motivation. Psychological Review, 50(3), 370-396.

McKeon, N. (2014). Food security governance: Empowering communities, regulating corporations. Routledge.

Moragues-Faus, A., \& Morgan, K. (2015). Reframing the foodscape: The emergent world of urban food policy. Environment and Planning A, 47(7), $1558-1573$.

Moragues-Faus, A., \& Marsden, T. (2017). The political ecology of food: Carving 'spaces of possibility' in a new research agenda. Journal of Rural Studies, 55, 275-288. 
Moragues-Faus, A., Sonnino, R., \& Marsden, T. (2017). Exploring European food system vulnerabilities: Towards integrated food security governance. Environmental Science \& Policy, 75, 184-215.

Morenoff, D. L. (2002). Lost food and liability: The good Samaritan food donation law Stoy. Food \& Drug LJ, 57, 107.

Nikolić, M., Glibetić, M., Gurinović, M., Milešević, J., Khokhar, S., Chillo, S., Abaravicius, J., Bordoni, A., \& Capozzi, F. (2014). Identifying critical nutrient intake in groups at risk of poverty in Europe: The CHANCE project approach. Nutrients, 6(4), 1374-1393.

Nussbaum, M. C. (1997). Capabilities and human rights. Fordham Law Review, 66(2).

Olsson, P., Gunderson, L., Carpenter, S., Ryan, P., Lebel, L., Folke, C., \& Holling, C. S. (2006). Shooting the rapids: Navigating transitions to adaptive governance of social-ecological systems. Ecology and Society, 11(1).

Oostindie, H., P. Hebinck, G. Villarreal, and A. Hebinck. (2016). Practice-Led Fns Redesigning in Europe. TRANSMANGO: EU KBBE.2013.2.5-01 Grant agreement no: 613532 .

Pattberg, P. (2006). The influence of global business regulation: Beyond good corporate conduct. Business and Society Review, 111(3), 241-268.

Pérez de Armiño, K. (2012) Erosion of rights, uncritical solidarity and food banks in Spain. In First world hunger revisited: Food Charity or the Right to Food? Riches, G., Silvasti, T., Eds.; Palgrave Macmillan: New York, NY, USA pp. 31-145.

Pfeiffer, S., Ritter, T., \& Hirseland, A. (2011). Hunger and nutritional poverty in Germany: Quantitative and qualitative empirical insights. Critical Public Health, 21(4), $417-428$.

Ponterotto, J. G. (2006). Brief note on the origins, evolution, and meaning of the qualitative research concept thick description. The Qualitative Report, $11(3), 538-549$.

Regulation (EU) (2014) No 223/2014 of the European Parliament and of the Council of 11 March 2014 on the Fund for European Aid to the Most Deprived (OJ L 72, 12.3.2014, p. 1). 
Reynolds, J. F., Stafford Smith, D. M., Lambin, E. F., TurnerII, B. L., Mortimore, M., Batterbury, S. P. J., Downing, T. E., Dowlatabadi, H., Fernandez, R. J., Herrick, J. E., Huber-Sannwal, E., Jiang, D. H., Leemans, R., Lynam, T., Maestre, F. T., Ayarzaand, M., \& Walker, B. (2007). Global desertification: Building a sciencefor dryland develop-ment. Science, 316 , $847-851$.

Riches, G., \& Silvasti, T. (Eds.). (2014). First world hunger revisited. Basingstoke: Palgrave MacMillian.

Riches, G. (2002). Food banks and food security: Welfare reform, human rights and social policy. Lessons from Canada? Social Policy \& Administration, 36(6), 648-663.

Riches, G. (2018). Food Bank nations: Poverty, corporate charity and the right to food. Routledge.

Rijke, J., Brown, R., Zevenbergen, C., Ashley, R., Farrelly, M., Morison, P., \& van Herk, S. (2012). Fit-for-purpose governance: A framework to make adaptive governance operational. Environmental Science \& Policy, 22, 73-84.

Rocha, C. (2009). Developments in national policies for food and nutrition security in Brazil. Development Policy Review, 27(1), 51-66.

Roep, D., Van Der Ploeg, J. D., \& Wiskerke, J. S. C. (2003). Managing technical-institutional design processes: Some strategic lessons from environmental co-operatives in the Netherlands. NJAS - Wageningen Journal of Life Sciences, 51(1-2), 195-217. https://doi.org/10.1016/S15735214(03)80033-7.

Rovati, G., \& Pesenti, L. (2015). Food poverty, food bank. Milan, Italy: Vita e pensiero.

Rovati, G., \& Campiglio, L. (2009). La povertà alimentare in Italia. Milano: Guerini \& Associati.

Rutten, M., Achterbosch, T. J., de Boer, I. J. M., Cuaresma, J. C., Geleijnse, J. M., Havlík, P., Heckelei, T., Ingram, J., Leip, A., Marette, S., van Meijl, H., Soler, L. G., Swinnen, J., van't Veer, P., Vervoort, J., Zimmermann, A., Zimmermann, K. L., \& Zurek, M. (2018). Metrics, models and foresight for 
European sustainable food and nutrition security: The vision of the SUSFANS project. Agricultural Systems, 163, 45-57.

Santini, C., \& Cavicchi, A. (2014). The adaptive change of the Italian food Bank foundation: A case study. British Food Journal, 116(9), 1446-1459.

Scholte, J. A. (Ed.). (2011). Building global democracy?: Civil society and accountable global governance. Cambridge University Press.

Sen, A. (1985). Commodities and capabilities. Amsterdam: North-Holland.

Silvasti, T., \& Karjalainen, J. (2014). Hunger in a Nordic welfare state:

Finland. In First world hunger revisited (pp. 72-86). Palgrave Macmillan UK.

Silvasti, T. (2015). Food aid - Normalising the abnormal in Finland. Social Policy and Society, 14(3), 471-482.

Sonnino, R., Lozano Torres, C., \& Schneider, S. (2014). Reflexive governance for food security: The example of school feeding in Brazil. Journal of Rural Studies, 36, 1-12.

Stimulanz, \& Ministry of Social Affairs and Employment. (2009). Toolkit: Samenwerking gemeenten en voedselbanken. Utrecht. https://www.landelijkeclientenraad.nl/Content/Downloads/Toolkit Stimulansz.pdf. Accessed 17 March 2015.

Stirling, A. (2014). From sustainability, through diversity to transformation: Towards more reflexive governance of technological vulnerability. Chapter in a. Hommels, J. Mesman, and W. Bijker, eds. In (2014) Vulnerability in Technological Cultures: New Directions in Research and Governance. Cambridge MA: MIT Press.

Sundkvist, Å., Milestad, R., \& Jansson, A. (2005). On the importance of tightening feedback loops for sustainable development of food systems. Food Policy, 30(2), 224-239.

Termeer, C. J., \& Bruinsma, A. (2016). ICT-enabled boundary spanning arrangements in collaborative sustainability governance. Current Opinion in Environmental Sustainability, 18, 91-98.

Termeer, C. J., Dewulf, A., Breeman, G., \& Stiller, S. J. (2015). Governance capabilities for dealing wisely with wicked problems. Administration \& 
Society, 47(6), 680-710.

Tomei, Gabriele, and Luca Caterino. 2013. Un'indagine Sulla Povertà Alimentare - $2^{\circ}$ Rapporto Sull'esclusione Sociale in Toscana. Anno 2013. Pisa.

van Meerkerk, I., \& Edelenbos, J. (2017). Facilitating conditions for boundary-spanning behaviour in governance networks. Public Management Review, 1-22.

Vlaholias-West, E., Thompson, K., Chiveralls, K., \& Dawson, D. (2018). The ethics of food charity. In P. Thompson \& D. Kaplan (Eds.), Encyclopedia of food and agricultural ethics. Dordrecht: Springer.

VNV. (2016). Feiten en Cijfers Voedselbanken Nederland. Houten. Retrieved from http:/voedselbankennederland.nl/wp-content/uploads/2016/12/feiten-encijfers-VBNL-per-31-12-2016.pdf

Voß, J. P., and Bornemann, B. (2011). The politics of reflexive governance: Challenges for designing adaptive management and transition management. Ecology and Society, 16(2).

Webb, K. L. (2013). Introduction-food banks of the future: Organizations dedicated to improving food security and protecting the health of the people they serve. Journal of Hunger \& Environmental Nutrition, 8(3), 257-260. https://doi.org/10.1080/19320248.2013.817169 .

Wittmayer, J. M., van Steenbergen, F., Rok, a., \& Roorda, C. (2015).

Governing sustainability: A dialogue between local agenda 21 and transition management. Local Environment, (June 2015), 1-17. https://doi.org/10.1080/13549839.2015.1050658 , 21, 939, 955

Yin, R. K. (2013). Case study research: Design and methods. Sage publications.

\footnotetext{
1 A Scopus search using key words "food banks" and "food poverty" yields 366 document results, with an exponential increase from 2007 to 2018.

${ }^{2}$ See e.g. Kim (2015) for a comparison of governance across US and South Korea, and GonzálezTorre and Coque (2016) on different profiles of food banks in Spain.

${ }^{3}$ https://www.eurofoodbank.org/en/impact-and-beneficiaries accessed on 17.12.17
} 
${ }^{4}$ For a more comprehensive reading of the forces that in the last half century have shaped the global food economy and embedded many social and ecological inequalities in it, we suggest Clapp (2016) and McKeon (2014).

${ }^{5}$ For example, in both Italy (Santini and Cavicchi 2014) and Finland (Silvasti 2015) the situation is that the national government, through its (agricultural and rural policy) agencies, operates directly with civil society and faith-based organisations to ensure widespread coverage of FEAD food distribution.

${ }^{6}$ Further detail on the case study in Italy is available in Arcuri, S., Galli F., Brunori G. 2016. "Local level analysis of FNS pathways in Italy: food assistance in Tuscany. Transmango: EU

KBBE.2013.2.5-01 Grant Agreement no: 613532. Available here:

https://www.researchgate.net/publication/309196346_local_level_analysis_of_fns_pathways_in_italythe_case_of_food_assistance_in_tuscany

${ }^{7}$ Good Samaritan Law, n. 155 approved on 16/07/2003 - Regulation on the Distribution of foodstuffs for purposes of Social Solidarity - Art. 1. The recognised organisations (such as nonprofit organisations of social utility (...), which carry out, for charitable purposes, free distribution of food products to the needy shall be treated as final consumers, for the proper state of transportation, storage and use of food" (Authors' translation).

${ }^{8}$ A new income measure is starting in December 2017 for the first time, introduced by the current government. The actual impact of such measure will be visible in the medium term.

${ }^{9}$ Further detail on the case study in the Netherlands is available in Hebinck A., Villarreal G., Oostindie H., and Hebinck P. 2015. D2.2 Transmango National Report: The Netherlands.

TRANSMANGO: EU KBBE.2013.2.5-01 Grant agreement no: 613532.

http://transmango.eu/publications .

${ }^{10}$ Further detail on the case study in Ireland is available in Carroll, B., and O'Connor D. 2016. "Local" Level Analysis of FNS Pathways in Ireland. Exploring Two Case Studies: Cork Food Policy Council and Bia Food Initiative. TRANSMANGO: EU KBBE.2013.2.5-01 Grant agreement no: 613532. https://transmango.files.wordpress.com/2017/09/d6-2-individual-case-study-reports.pdf 11 During the conducting of this research in spring and summer 2016, this initiative was known as Bia Food Initiative. In October 2016, it was rebranded and launched as Food Cloud Hubs.

12 Origin Green is a certification programme which aims to promote the sustainability of Irish food production practices. Food manufacturers must set a number of sustainable practice targets one of which might be to divert surplus food from waste streams, thus satisfying social and environmental targets. Engaging with FCH facilitates working towards such targets.

13 FEAD is a social programme, the objectives of which are to address European Union's citizens' most basic needs, for food and other items. Its key aim is to tackle the causes and outcomes of poverty and social exclusion (Caraher 2015). 